\title{
The effect of thiazolidinediones on bone mineral density and bone turnover: systematic review and meta-analysis
}

\author{
Emma O. Billington ${ }^{1,2} \cdot$ Andrew Grey $^{2} \cdot$ Mark J. Bolland $^{2}$
}

Received: 5 March 2015 / Accepted: 19 May 2015 /Published online: 25 June 2015

(C) Springer-Verlag Berlin Heidelberg 2015

\begin{abstract}
Aims/hypothesis Thiazolidinediones (TZDs) are associated with an increased risk of fracture but the mechanism is unclear. We sought to determine the effect of TZDs on bone mineral density (BMD) and bone turnover markers.

Methods PubMed, EMBASE and Cochrane CENTRAL databases were searched from inception until January 2015 for randomised controlled trials comparing TZDs with metformin, sulfonylureas or placebo, and those reporting changes in BMD and/or bone turnover markers. The primary outcome was percentage change in BMD from baseline and results were pooled with random effects meta-analyses.

Results In all, 18 trials were included in the primary analyses and another two were included in the sensitivity analyses $(n=3,743,50 \%$ women, mean age 56 years, median trial duration 48 weeks). TZDs decreased BMD at the lumbar spine (difference $-1.1 \%$ [95\% CI $-1.6,-0.7] ; p<0.0001$ ), total hip $(-1.0 \%[-1.4,-0.6] ; p<0.0001)$ and forearm $(-0.9 \%[-1.6$, $-0.3] ; p=0.007)$. There were statistically non-significant decreases in BMD at the femoral neck $(-0.7 \%[-1.4,0.0]$; $p=0.06)$ and total body $(-0.3 \%[-0.5,0.0] ; p=0.08)$. Five trials $(n=450)$ showed no statistically significant difference in percentage change in BMD between the TZD group and
\end{abstract}

Electronic supplementary material The online version of this article (doi:10.1007/s00125-015-3660-2) contains peer-reviewed but unedited supplementary material, which is available to authorised users.

Emma O. Billington

e.billington@auckland.ac.nz

1 Division of Endocrinology, University of Calgary, Calgary, Canada

2 Bone \& Joint Research Group, Faculty of Medical and Health Sciences, University of Auckland, 85 Park Road, Grafton, Auckland 1010, New Zealand controls up to 1 year following TZD withdrawal. In 14 trials, the effect of TZD treatment on turnover markers varied considerably between individual studies.

Conclusions/interpretation Treatment with TZDs results in modest bone loss that may not be reversed 1 year after cessation of treatment.

Keywords Bone density $\cdot$ Diabetes mellitus $\cdot$ Meta-analysis · Pioglitazone $\cdot$ Rosiglitazone $\cdot$ Systematic review .

Thiazolidinediones

$\begin{array}{ll}\text { Abbreviations } \\ \text { ADOPT } & \text { A Diabetes Outcome Progression Trial } \\ \text { BMD } & \text { Bone mineral density } \\ \text { bsALP } & \text { Bone-specific alkaline phosphatase } \\ \text { CTX } & \quad \beta \text {-C-terminal telopeptide of type I collagen } \\ \text { IGT } & \text { Impaired glucose tolerance } \\ \text { PINP } & \text { Procollagen type I N-terminal propeptide } \\ \text { PPAR- } \gamma & \text { Peroxisome proliferator activated receptor- } \gamma \\ \text { PRISMA } & \begin{array}{l}\text { Preferred Reporting Items for Systematic } \\ \text { Reviews and Meta-Analyses }\end{array} \\ \text { RCT } & \begin{array}{l}\text { Randomised controlled trial } \\ \text { TZD }\end{array} \\ \text { Thiazolidinedione }\end{array}$

\section{Introduction}

Thiazolidinediones (TZDs), such as rosiglitazone and pioglitazone, are agonists of the peroxisome proliferator activated receptor- $\gamma$ (PPAR- $\gamma$ ) isoform that promote insulin sensitisation [1]. These agents improve glycaemic control in patients with type 2 diabetes and slow the development of diabetes in persons with impaired glucose tolerance (IGT) $[2,3]$. 
However, TZDs have also been associated with an increased risk of fracture $[4,5]$. Post-hoc analyses of large randomised controlled trials (RCTs) have demonstrated a 1.5- to 2-fold increased risk of distal extremity fracture in women with diabetes receiving TZDs [6-8]. In addition, observational studies have reported an increased risk of fracture in the axial skeleton with TZD use in both women and men $[9,10]$.

The mechanism by which TZDs increase fracture risk remains unclear. At a cellular level, PPAR- $\gamma$ acts on mesenchymal stem cells to preferentially promote differentiation into adipogenic cell lineages at the expense of osteoblastogenesis [11]. Some clinical studies report increased loss of bone mineral density (BMD) with TZDs [12-15], but the effects on bone turnover markers have been inconsistent, with evidence for both reduced bone formation [14, 16, 17] and increased bone resorption $[12,17,18]$. It is possible to detect biologically significant effects in surrogate endpoints for fracture, such as BMD and bone turnover, in much smaller cohorts than are required for investigation of effects on fracture incidence. Therefore, we conducted a systematic review and metaanalysis of all RCTs that assessed the effects of TZDs on BMD and bone turnover markers to determine whether or not bone loss, due to an uncoupling of bone formation and resorption, may account for the increased risk of fracture in patients taking TZDs. We also investigated whether or not the effect of TZDs on BMD and bone turnover markers varies depending on patient characteristics (sex, hormonal status, comorbidities) or intervention characteristics (type of TZD, dose, treatment duration), and whether or not withdrawal of therapy results in reversal of any TZD-induced changes in BMD.

\section{Methods}

In January 2014, we searched PubMed, EMBASE and Cochrane CENTRAL databases from inception, without limits, for RCTs of TZDs with BMD and/or bone turnover markers as an endpoint. The complete search strategy is shown in the electronic supplementary material (ESM) Table 1. We also searched three clinical trials registries (www.clinicaltrials.gov, www.controlled-trials.com/mrct and www.anzctr.org.au, all accessed 20/01/2014) for ongoing trials, and hand-searched the reference lists of identified articles and recent review articles for relevant studies. An updated literature search of all databases was performed in January 2015.

We included RCTs carried out in adults aged $\geq 18$ years that compared TZD treatment with a control group that received placebo, metformin or a sulfonylurea, and reported changes in BMD or bone turnover markers during the intervention period. Titles and abstracts were screened by one author
(E. O. Billington) and the full text of potentially eligible articles were reviewed by two authors independently (E. O. Billington, M. J. Bolland). The process of selection for inclusion in the systematic review and meta-analysis is shown in Fig. 1.

We extracted information from each study on participant characteristics, interventions, study design, outcome measures, funding source and investigator conflicts of interest. Where necessary, we clarified data uncertainties with the study authors. Data were extracted by a single author (E. O. Billington) using a pre-specified extraction form and checked by a second author (M. J. Bolland). Any discrepancies were resolved through discussion. Risk of bias was assessed as recommended in the Cochrane review handbook [19] and the Preferred Reporting Items for Systematic Reviews and MetaAnalyses (PRISMA). The primary endpoint was percentage change in BMD from baseline to the end of the intervention period at the lumbar spine, femoral neck, total hip, forearm and total body. Secondary endpoints were percentage change in bone turnover markers (procollagen type I N-terminal propeptide [PINP], osteocalcin, $\beta$-C-terminal telopeptide of type I collagen $[\mathrm{CTX}]$ and bone-specific alkaline phosphatase [bsALP]) from baseline to the end of the intervention period, and percentage change in BMD and bone turnover markers

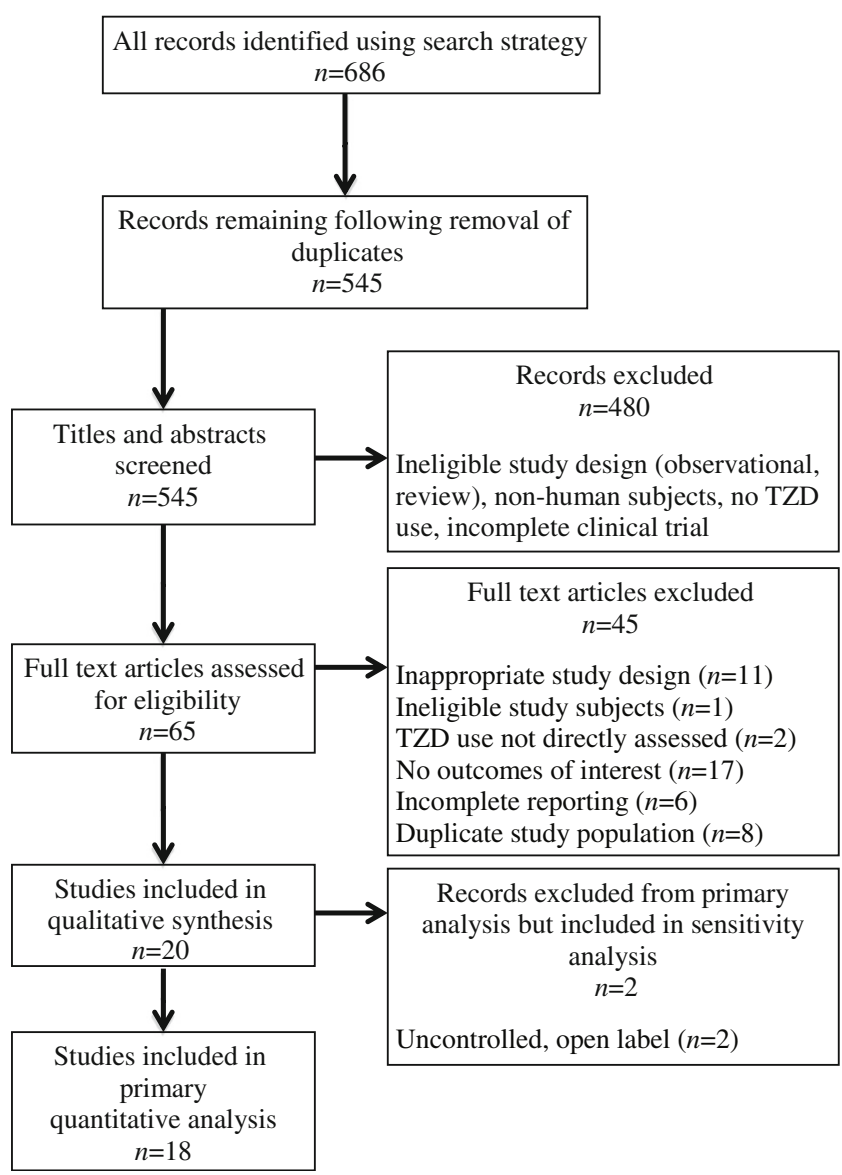

Fig. 1 PRISMA flow sheet indicating process of selection of studies for inclusion in systematic review and meta-analysis 
following withdrawal of the intervention. Fractures were not assessed as most of the studies designed to assess change in BMD were underpowered and of inadequate duration to assess fracture outcomes. Furthermore, the risk of fractures with TZD use has been previously established in meta-analyses [4, 5]. Where data were presented in figures, we used digital calipers to extract the data. For studies that presented absolute data rather than percentage change from baseline [13, 16, 20-23], we calculated the mean percentage change from the raw data and calculated the SD of the percentage change using the approaches described in the Cochrane review handbook [24].

Data were pooled using random effects meta-analysis and heterogeneity was assessed using the $I^{2}$ statistic $\left(I^{2}>50 \%\right.$ was considered significant heterogeneity). Funnel plots and Egger's regression model were used to assess for the likelihood of publication bias. We undertook sensitivity analyses in pre-specified subgroups (sex, hormonal status, indication for TZD, type of TZD, treatment dose, trial duration). All tests were two-tailed, and $p$ values $<0.05$ were considered statistically significant. Analyses were performed using Comprehensive Meta-Analysis (Version 2, Biostat, Englewood, NJ, USA).

\section{Results}

Literature search results We identified 18 RCTs that met all the inclusion criteria $[12-15,17,18,21-23,25-33]$. Two open-label studies had a control group that received no treatment $[16,20]$ and these were included only in the sensitivity analysis. In our initial search, we identified one completed study at www.clinicaltrials.gov (accessed 20/01/2014) that met our inclusion criteria, but no results had been reported [34]. Results were subsequently published on www. clinicaltrials.gov (accessed 05/01/2015), but neither BMD nor bone turnover marker outcomes were reported and these variables have been removed from the list of outcomes. We requested data from the study contact, but they were unable to provide us with any study results. One conference abstract [35] was potentially eligible for inclusion but did not contain enough information for adequate data extraction and we were unable to contact the study author to obtain further data.

Study characteristics The study design and selected baseline characteristics of the 18 RCTs in the primary analyses and the two open-label studies included in the sensitivity analysis are summarised in Table 1 . These 20 studies involved 3,743 participants, of whom $50 \%$ were women and the mean age was 56 years. Baseline BMD data are shown in ESM Table 2. Seven studies included only women and one included only men; 12 studies involved patients with type 2 diabetes or IGT, one study had patients with metabolic syndrome, four studies included patients with HIV, one study had women with polycystic ovarian syndrome and two studies involved healthy postmenopausal women.

Rosiglitazone was studied in 12 trials and pioglitazone in eight studies. One multi-arm study administered pioglitazone in one arm and balaglitazone in the other two arms [29]. Results from these three TZD arms were pooled for the primary analyses. One study had a $2 \times 2$ factorial design, whereby one treatment arm consisted of rosiglitazone or placebo and the other treatment arm consisted of metformin or placebo [27]. For the primary analyses, we compared the two pooled groups who received rosiglitazone with the two pooled groups who did not. The control group received placebo in 12 studies, metformin in four studies, metformin or placebo in one study, and metformin and glibenclamide (known as glyburide in the USA and Canada) in one study. Eight studies were of $\leq 6$ months duration and 12 were of $>6$ months duration. Three studies extended beyond 12 months, but none were longer than 25 months $[13,16,26]$. Five studies included follow-up periods after withdrawal of TZD treatment, ranging 2452 weeks $[12,14,15,25,28]$. Fourteen studies reported BMD and 14 reported bone turnover marker outcomes.

ESM Table 3 shows our assessment of the risk of bias; in all, 16 trials were assessed as having a low risk of bias [12-15, $17,22,23,25-33]$, two as having a moderate risk $[18,21]$ and two as having high risk of bias $[16,20]$. Ten studies were conducted and/or funded by industry, and investigator conflicts of interest were reported for eight studies.

Changes in BMD Fourteen studies ( $n=1,734$ patients) were included in the primary analyses [12-15, 21-23, 25-30, 32]. Figure 2 shows that TZDs decreased BMD compared with controls at the lumbar spine (difference $-1.1 \%[95 \%$ CI $-1.6,-0.7] ; p<0.0001)$, total hip $(-1.0 \%[-1.4,-0.6]$; $p<0.0001)$ and forearm $(-0.9 \%[-1.6,-0.3] ; p=0.007)$. Statistically non-significant decreases were seen in BMD at the femoral neck $(-0.7 \%[-1.4,0.0] ; p=0.06)$ and total body $(-0.3 \%[-0.5,0.0 ; p=0.08])$. Inclusion of the open-label RCT [16] in a sensitivity analysis did not change the effect estimates although the femoral neck result became statistically significant $(p=0.002)$. No consistent evidence of publication bias was found for any of these outcomes based on visual inspection of funnel plots and results from the Egger's test.

We performed pre-specified sensitivity analyses in subgroups to determine whether or not restricting the pooled analysis to studies with certain patient or intervention characteristics would alter our findings. The results of analyses restricted to women, postmenopausal women, cohorts with diabetes mellitus or IGT, RCTs of rosiglitazone, RCTs of pioglitazone, RCTs of low-dose TZDs (average daily dose $\leq 4 \mathrm{mg}$ rosiglitazone or $\leq 30 \mathrm{mg}$ pioglitazone), RCTs lasting $\leq 26$ weeks, RCTs lasting $>26$ weeks, RCTs with metformin as a control and RCTs of placebo as a control were all similar to the results for the primary analyses (summarised in ESM 


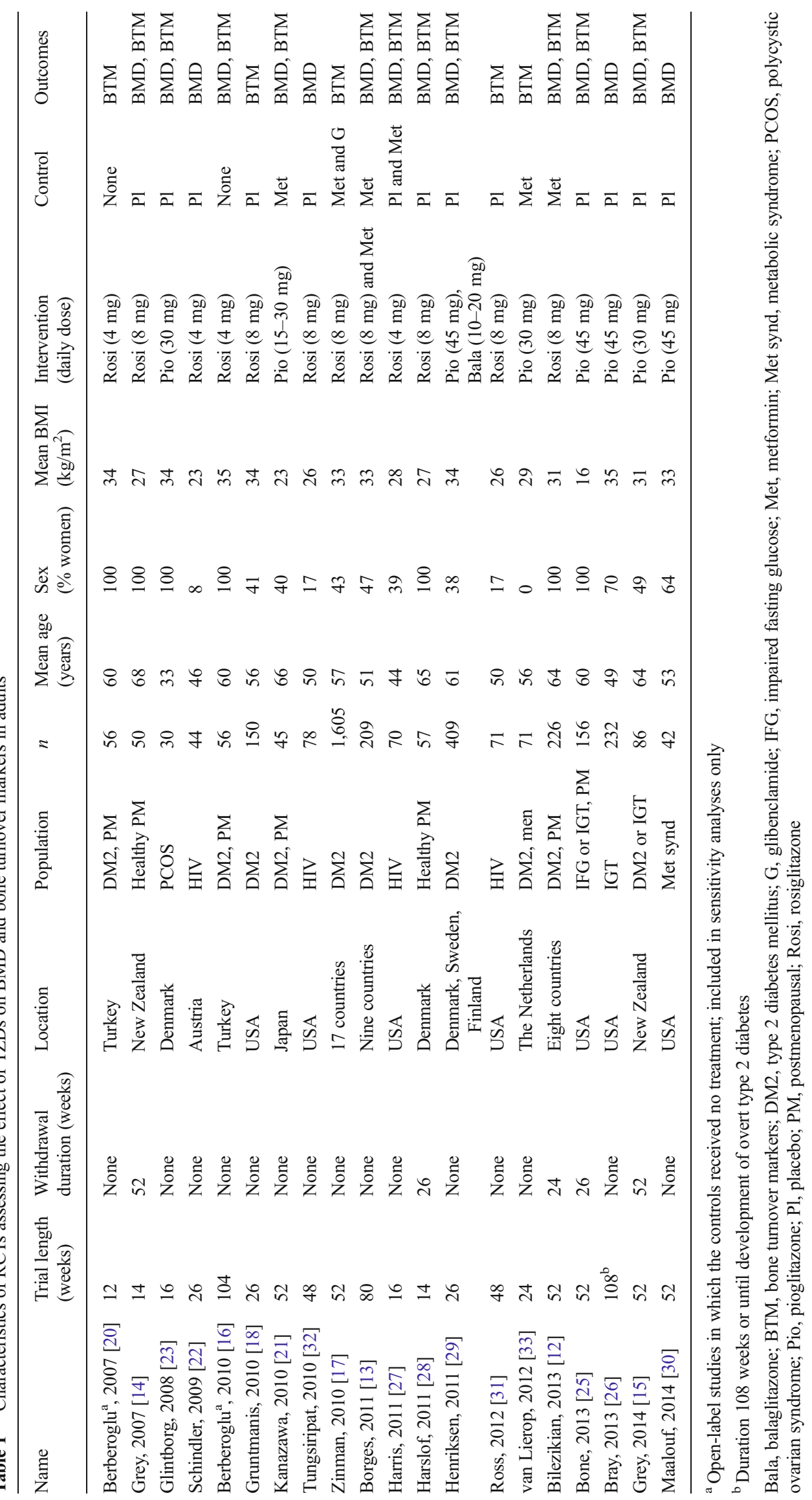




\begin{tabular}{|c|c|c|c|}
\hline Authors [ref.] & $\begin{array}{l}\text { Weighted mean difference } \\
\text { in BMD }(\%)[95 \% \mathrm{Cl}]\end{array}$ & & $\begin{array}{l}\text { Weight } \\
(\%)\end{array}$ \\
\hline $\begin{array}{l}\text { Lumbar spine } \\
\quad \text { Grey et al (2007) [14] }\end{array}$ & & $-1.0(-2.2,0.2)$ & 13 \\
\hline Glintborg et al (2008) [23] & & $-1.3(-3.0,0.4)$ & 7 \\
\hline Schindler et al (2009) [22] & & $-3.9(-9.5,1.7)$ & 1 \\
\hline Kanazawa et al (2010) [21] & - & $-1.2(-3.1,0.8)$ & 5 \\
\hline Borges et al (2011) [13] & & $-2.2(-3.7,-0.7)$ & 9 \\
\hline Harslof et al (2011) [28] & & $-0.6(-1.6,0.3)$ & 21 \\
\hline Bilezikian et al (2013) [12] & & $-1.5(-2.6,-0.3)$ & 14 \\
\hline Bone et al (2013) [25] & & $-1.0(-2.0,0.1)$ & 18 \\
\hline Grey et al (2014) [15] & & $-0.7(-2.1,0.7)$ & 10 \\
\hline Maalouf et al (2014) [30] & & $-2.0(-4.7,0.6)$ & 3 \\
\hline Total & & $-1.1(-1.6,-0.7)$ & $p<0.0001$ \\
\hline \multicolumn{4}{|c|}{ Test for heterogeneity: $l^{2}=0 \%, p=0.8$} \\
\hline $\begin{array}{l}\text { Total hip } \\
\quad \text { Grey et al (2007) [14] }\end{array}$ & & $-1.7(-2.7,-0.7)$ & 13 \\
\hline Glintborg et al (2008) [23] & & $-1.1(-2.5,0.4)$ & 7 \\
\hline Schindler et al (2009) [22] & & $0.5(-1.3,2.4)$ & 5 \\
\hline Borges et al (2011) [13] & & $-1.5(-2.5,-0.5)$ & 14 \\
\hline Harslof et al (2011) [28] & & $-0.3(-1.4,0.8)$ & 11 \\
\hline Bilezikian et al (2013) [12] & & $-0.9(-2.0,0.2)$ & 12 \\
\hline Bone et al (2013) [25] & & $-0.6(-1.3,0.2)$ & 19 \\
\hline Grey et al (2014) [15] & & $-1.2(-2.1,-0.2)$ & 15 \\
\hline Maalouf et al (2014) [30] & - & $-2.2(-4.1,-0.3)$ & 5 \\
\hline Total & & $-1.0(-1.4,-0.6)$ & $p<0.0001$ \\
\hline \multicolumn{4}{|c|}{ Test for heterogeneity: $l=19 \%, p=0.3$} \\
\hline $\begin{array}{l}\text { Femoral neck } \\
\quad \text { Grey et al (2007) [14] }\end{array}$ & & $-0.9(-2.3,0.5)$ & 11 \\
\hline Glintborg et al (2008) [23] & & $-2.0(-3.9,-0.2)$ & 8 \\
\hline Schindler et al (2009) [22] & & $1.2(-0.1,2.5)$ & 12 \\
\hline Kanazawa et al (2010) [21] & & $0.6(-1.4,2.5)$ & 8 \\
\hline Borges et al (2011) [13] & & $-0.7(-1.8,0.4)$ & 13 \\
\hline Harslof et al (2011) [28] & & $-1.6(-3.2,0.0)$ & 9 \\
\hline Bilezikian et al (2013) [12] & & $-1.7(-3.1,-0.3)$ & 11 \\
\hline Bone et al (2013) [25] & & $-0.9(-2.1,0.4)$ & 12 \\
\hline Grey et al (2014) [15] & & $-1.2(-2.3,-0.1)$ & 13 \\
\hline Maalouf et al (2014) [30] & & $2.9(-0.6,6.4)$ & 3 \\
\hline Total & & $-0.7(-1.4,0.0)$ & $p=0.06$ \\
\hline \multicolumn{4}{|c|}{ Test for heterogeneity: $I^{2}=56 \%, p=0.02$} \\
\hline $\begin{array}{l}\text { Forearm } \\
\text { Kanazawa et al (2010) [21] }\end{array}$ & & $-1.7(-3.9,0.5)$ & 10 \\
\hline Borges et al (2011) [13] & 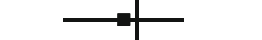 & $-0.4(-2.2,1.4)$ & 14 \\
\hline Bone et al (2013) [25] & & $-0.9(-1.9,0.1)$ & 46 \\
\hline Grey et al (2014) [15] & & $-1.0(-2.2,0.3)$ & 30 \\
\hline Total & $\rightarrow-$ & $-0.9(-1.6,-0.3)$ & $p=0.007$ \\
\hline \multicolumn{4}{|c|}{ Test for heterogeneity: $I^{2}=0 \%, p=0.8$} \\
\hline \multicolumn{4}{|c|}{ Total body } \\
\hline Grey et al (2007) [14] & & $-0.4(-1.3,0.5)$ & 10 \\
\hline Tungsiripat et al (2010) [32] & & $-0.1(-1.1,0.9)$ & 7 \\
\hline Borges et al (2011) [13] & & $0.0(-1.8,1.8)$ & 2 \\
\hline Harris et al (2011) [27] & & $-0.1(-0.9,0.7)$ & 12 \\
\hline Henriksen et al (2011) [29] & & $0.0(-0.5,0.5)$ & 29 \\
\hline Bone et al (2013) [25] & & $-0.1(-0.8,0.6)$ & 16 \\
\hline Bray et al (2013) [26] $]^{\mathrm{a}}$ & $\rightarrow-$ & $-1.4(-2.6,-0.2)$ & 5 \\
\hline Grey et al (2014) [15] & $\rightarrow$ & $-0.5(-1.2,0.1)$ & 19 \\
\hline Total & 4 & $-0.3(-0.5,0.0)$ & $p=0.08$ \\
\hline Test for heterogeneity: $I^{2}=C$ & $\%, p=0.6$ & & \\
\hline
\end{tabular}

Fig. 2 Meta-analyses of the effects of TZDs on the percentage change in

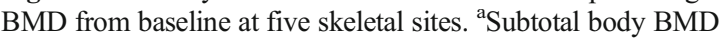

Table 4). For this reason, and because most subgroups contained fewer than five studies, we did not formally test for interactions between the subgroups. The number of studies was insufficient to assess effects in men or in cohorts with HIV.

Five studies reported on changes in BMD following withdrawal of TZD treatment for 24-52 weeks [12, 14, 15, 25, 28]. Figure 3 shows that there were no statistically significant differences in percentage change in BMD between the TZD group and controls following treatment withdrawal.

Changes in bone turnover Change in bone turnover markers varied considerably between individual studies and significant heterogeneity was observed for all turnover markers, except osteocalcin. The pooled summary statistics (CTX difference $11.0 \%$ [95\% CI 0.5, 21.5]; $p=0.04$; bsALP 1.0\% [-5.6, 7.6]; $p=0.80 ;$ PINP $3.7 \%[-5.1,12.5] ; p=0.40$; osteocalcin $-0.8 \%$ $[-5.2,3.6] ; p=0.70)$ may, therefore, not be generalisable. Of

\begin{tabular}{|c|c|c|c|}
\hline Authors [ref.] & $\begin{array}{l}\text { Weighted mean difference } \\
\text { in BMD }(\%)[95 \% \mathrm{Cl}]\end{array}$ & & $\begin{array}{l}\text { Weight } \\
(\%)\end{array}$ \\
\hline \multicolumn{4}{|l|}{ Lumbar spine } \\
\hline Grey et al (2007) [14] & & $-1.1(-2.7,0.5)$ & 15 \\
\hline Harslof et al (2011) [28] & & $-0.1(-1.2,0.9)$ & 23 \\
\hline Bilezikian et al (2013) [12] & & $-0.8(-2.0,0.5)$ & 20 \\
\hline Bone et al (2013) [25] & & $-0.2(-1.1,0.8)$ & 24 \\
\hline Grey et al (2014) [15] & $\rightarrow$ & $1.8(0.4,3.2)$ & 18 \\
\hline \multirow{2}{*}{\multicolumn{4}{|c|}{ Test for heterogeneity: $l^{2}=57 \%, p=0.05$}} \\
\hline & & & \\
\hline \multicolumn{4}{|l|}{ Total hip } \\
\hline Grey et al (2007) [14] & $\longrightarrow$ & $1.3(0.0,2.6)$ & 14 \\
\hline Harslof et al (2011) [28] & {$[-$} & $0.3(-0.8,1.5)$ & 16 \\
\hline Bilezikian et al (2013) [12] & & $0.5(-0.3,1.4)$ & 23 \\
\hline Bone et al (2013) [25] & & $-0.2(-0.9,0.6)$ & 26 \\
\hline Grey et al (2014) [15] & & $-0.7(-1.6,0.3)$ & 21 \\
\hline \multicolumn{3}{|c|}{ Test for heterogeneity: $l^{2}=45 \%, p=0.12$} & $p=0.6$ \\
\hline \multicolumn{4}{|l|}{ Femoral neck } \\
\hline Grey et al (2007) [14] & & $-0.3(-1.8,1.3)$ & 18 \\
\hline Harslof et al (2011) [28] & & $0.7(-1.2,2.6)$ & 12 \\
\hline Bilezikian et al (2013) [12] & & $-0.1(-1.7,1.6)$ & 17 \\
\hline Bone et al (2013) [25] & & $-0.6(-1.9,0.7)$ & 28 \\
\hline Grey et al (2014) [15] & & $-0.3(-1.6,1.1)$ & 25 \\
\hline $\begin{array}{ll}\text { Total } \\
\end{array}$ & & $-0.2(-0.9,0.5)$ & $p=0.6$ \\
\hline \multicolumn{4}{|c|}{ Test for heterogeneity: $l^{2}=0 \%, p=0.9$} \\
\hline \multicolumn{4}{|l|}{ Forearm } \\
\hline Bone et al (2013) [25] & - & $0.3(-0.6,1.3)$ & 74 \\
\hline Grey et al (2014) [15] & $=$ & $1.0(-0.6,2.7)$ & 26 \\
\hline Total & - & $0.5(-0.3,1.3)$ & $p=0.2$ \\
\hline \multicolumn{4}{|c|}{ Test for heterogeneity: $I^{2}=0 \%, p=0.5$} \\
\hline \multicolumn{4}{|l|}{ Total body } \\
\hline Grey et al (2007) [14] & & $-0.4(-1.4,0.6)$ & 21 \\
\hline Bone et al (2013) [25] & - & $0.5(-0.3,1.2)$ & 35 \\
\hline Grey et al (2014) [15] & & $0.1(-0.6,0.8)$ & 44 \\
\hline Total & & $0.1(-0.3,0.6)$ & $p=0.6$ \\
\hline Test for heterogeneity: $I^{2}=0 \%$, & $p=0.4$ & & \\
\hline
\end{tabular}

Fig. 3 Meta-analysis of the effects of TZD cessation on the percentage change in BMD at five skeletal sites from the time of TZD withdrawal until the end of the follow-up period 
10 studies reporting on CTX, five reported significant increases with TZDs $[12,17,18,28,33]$ and five showed no effect [13-15, 25, 31]. Of the five studies reporting on bsALP, one reported a significant increase with TZDs [12] and no effect was seen in four $[13,17,25,28]$. Of the 11 studies reporting on PINP, three reported significant increases with TZDs [12, 18, 33], two showed significant decreases [27, $31]$ and six found no effect $[13-15,17,25,28]$. Of the six studies that reported on osteocalcin, one demonstrated a significant decrease with TZDs [14] and five showed no effect $[21,23,25,28,31]$. Inclusion of the results of an open-label RCT [20] in a sensitivity analysis did not alter our findings. We did not formally assess for statistically significant interactions between pre-specified subgroups because there were insufficient studies; however, heterogeneity between studies did not appear to be related to patient characteristics, type of TZD, TZD dose, type of control or study duration.

Only two studies reported withdrawal data for markers of bone turnover $[12,25]$. Pooling of these results did not identify significant changes in turnover markers following cessation of treatment with TZDs (data not shown).

\section{Discussion}

In these meta-analyses, treatment with TZDs for 3-24 months reduced BMD at the lumbar spine, proximal femur and forearm by $0.7 \%-1.1 \%$ compared with placebo or metformin. After cessation of TZD therapy, there was no further loss of $\mathrm{BMD}$, but there was also no regain of the earlier BMD loss. The decreases in BMD were consistent in different RCTs, across different patient populations, in RCTs of different TZD agents and doses, in RCTs with metformin or placebo as a control and in trials lasting $\leq 6$ or $>6$ months. By contrast, there was marked heterogeneity in changes of most bone turnover markers with TZDs.

Our analyses demonstrate that TZDs cause modest bone loss, an effect that is apparent by 6 months of treatment. An important clinical question is whether or not this bone loss persists with ongoing treatment. If there is little further BMD loss after 1 year of TZD treatment, the decreases in BMD of $0.7 \%-1.1 \%$ observed in the meta-analyses are likely to be clinically insignificant as they are much smaller than the normal variation of BMD in the population, and are equivalent to the average loss of BMD over 1 year in postmenopausal women [36]. However, if BMD loss was cumulative at a rate of $1 \%$ per year, such decreases would be clinically important after 5-10 years of treatment. Existing clinical trials are unable to provide a definitive answer to this question. While bone loss appeared to be similar in studies of $\leq 6$ months and $>6$ months duration, the meta-analyses did not have sufficient power to detect small differences in BMD changes between these subgroups of trials as only three studies extended beyond 1 year $[13,16,26]$. In one of these extended studies, BMD loss at the lumbar spine was greater after 80 weeks than after 56 weeks, arguing against a plateau [13]. Results of an observational cohort study by Schwartz and colleagues suggest that long-term treatment with TZDs may result in progressive bone loss [37]. They found that persons who used TZDs for at least 2 years demonstrated progressive annual bone loss of $-1.6 \%$ at the total hip and $-1.1 \%$ at the whole body lumbar spine sub-region. By contrast, the annual change in BMD amongst non-TZD users was $-0.4 \%$ at the hip and + $1.1 \%$ at the lumbar sub-region. However, this was not a controlled trial, and only 15 patients received $>2$ years of therapy. Given the nature of type 2 diabetes as a chronic, life-long disease, many patients will be prescribed TZDs with the expectation of continuing treatment for at least 5-10 years. Therefore, determining the long-term effects of TZDs on BMD is an important safety question that needs to be addressed with high priority.

Our results raise the possibility that TZDs may increase skeletal fragility by mechanisms other than decreasing BMD. The results of the A Diabetes Outcome Progression Trial (ADOPT) suggest that the 2-fold increased risk of fracture does not become evident until almost 2 years of treatment [8], and an extrapolation of the results from our meta-analyses would suggest a $2 \%$ decrease in BMD by this time. This is unlikely to fully explain the changes in fracture risk seen in ADOPT and other RCTs [6-8]. The majority of fractures in patients taking TZDs in randomised trials occur at cortical sites (humerus, distal forearm, tibia) [4, 5], but we did not observe a greater magnitude of bone loss at cortical sites than trabecular sites. Studies in both rodents and humans indicate that TZD exposure is associated with changes in cortical microarchitecture, which will not necessarily be evident on dual-energy x-ray absorptiometry [38-40]. Animal studies have also demonstrated that TZD exposure results in increased cortical porosity and decreased cortical thickness in the absence of significant changes in volumetric BMD [38, 39]. In women using TZDs, reduction in polar strength strain index at highly cortical sites has been observed [40]. Therefore, while TZD-mediated declines in BMD may result in an increased propensity for fracture, particularly if bone loss is sustained with long-term treatment, the excess distal extremity fractures observed in patients taking TZDs may be better explained by changes in microarchitecture at cortical sites.

Assessment of the effect of TZDs on bone turnover markers did not help to elucidate the mechanism by which these medications increase fracture risk. Change in bone turnover markers varied considerably between individual studies. While HIV, anti-retroviral treatment, diabetes, glycaemic control and the postmenopausal state are all known to influence concentrations of turnover markers [41-43], no consistent changes in these markers were observed within the different study populations incorporated in this meta-analysis. Our 
findings corroborate the results of animal studies, which have also reported inconsistent effects of TZDs on bone turnover [11]. In addition to being heterogeneous, changes in bone turnover markers did not correspond with the observed changes in BMD in this meta-analysis. Furthermore, several included studies that assessed both turnover markers and BMD did not observe a correlation between the two [12, 13, 23, 29]. This is not surprising as the assessment of turnover marker concentrations is associated with considerable within-patient variability [41] and they do not always correspond with small changes in BMD [44]. Within the subgroup of the ADOPT trial in whom bone turnover markers were measured, Zinman et al did not observe differences amongst those who fractured and those who did not [17]. Therefore, turnover markers appear to have a limited role in the assessment of skeletal response to TZD therapy.

This is the first meta-analysis to assess the effect of TZD discontinuation on BMD. BMD did not change significantly at any site following TZD withdrawal, suggesting that the BMD loss with TZD therapy is not reversible in the year following discontinuation. Although the mechanism by which TZDs act on bone is complex and not yet fully understood, these agents appear to have a direct effect on the differentiation of both osteoblasts and osteoclasts $[11,45]$. PPAR- $\gamma$ has been shown in preclinical studies to promote the differentiation of mesenchymal stem cells into adipocytes rather than osteoblasts [46], and to promote osteoclast differentiation and increase osteoclast numbers [45]. In addition, exposure to TZDs appears to induce osteoblast and osteocyte apoptosis [47-49]. A reduction in the number of osteocytes and osteoblasts has the potential for prolonged negative effects on bone, given the relatively long differentiation periods and lifespans of these cell types [50]. This may explain why there does not appear to be any regain of lost BMD following cessation of TZDs.

This meta-analysis has several limitations. Although we identified 20 eligible RCTs, there were not enough studies to carry out detailed subgroup analyses and only three studies had outcome data beyond 1 year. There was marked heterogeneity amongst studies of bone turnover markers and we were unable to draw conclusions regarding the effect of TZDs on turnover markers. Despite its limitations, this study has several strengths. It is the largest meta-analysis to evaluate the effect of TZDs on bone density and bone turnover markers, and the only one to assess the effect of TZD withdrawal on these variables. We are aware of two previous metaanalyses of the effect of TZDs on BMD [4, 51]. The earlier analysis identified two small RCTs published prior to June 2008 involving 95 participants [4]. The more recent analysis included seven studies [51]. Our meta-analysis provides important additional information by including more studies, previously unpublished data from some studies, more BMD sites, data from withdrawal studies and data from bone turnover markers.
For physicians who treat patients with TZDs, these results raise an important safety flag. Longer-term studies assessing the effects of both TZD treatment and withdrawal on BMD are needed, together with a better understanding of the mechanism by which TZDs affect fracture risk. Until this information is available, it may be prudent for clinicians to periodically monitor BMD in older patients taking TZDs and to consider avoiding these agents altogether in individuals at high risk of fracture, such as postmenopausal women with clinical risk factors for fracture.

Acknowledgements We would like to thank the following authors of the included studies for providing us with additional information to facilitate our analyses: G. Bray (Louisiana State University, Baton Rouge, LA, USA), K. Schindler (Medical University of Vienna, Vienna, Austria), K. Mulligan (University of California, San Francisco, CA, USA), T. Brown (Johns Hopkins University, Baltimore, MD, USA) and N. Maalouf (University of Texas Southwestern, Dallas, TX, USA).

Funding This study was funded by the Health Research Council (HRC) of New Zealand. MB is the recipient of a Sir Charles Hercus Health Research Fellowship.

Duality of interest AG is a shareholder in Auckland Bone Density, which provides bone density measurements. All other authors declare that there is no duality of interest associated with their contribution to this manuscript.

Contribution of authors All authors (EB, AG, MB) made significant contributions to the creation of this manuscript. EB, AG, and MB developed the research question and study design. The literature search was conducted by EB. Data extraction was carried out by EB and MB. Writing and revision of the manuscript was done by all three authors. MB is responsible for the integrity of the work as a whole. All three authors have approved the final version of this manuscript for publication.

\section{References}

1. Yki-Jarvinen H (2004) Thiazolidinediones. N Engl J Med 351: 1106-1118

2. Dream Trial Investigator, Gerstein HC, Yusuf S et al (2006) Effect of rosiglitazone on the frequency of diabetes in patients with impaired glucose tolerance or impaired fasting glucose: a randomised controlled trial. Lancet 368:1096-1105

3. Kahn SE, Haffner SM, Heise MA et al (2006) Glycemic durability of rosiglitazone, metformin, or glyburide monotherapy. $\mathrm{N}$ Engl J Med 355:2427-2443

4. Loke YK, Singh S, Furberg CD (2009) Long-term use of thiazolidinediones and fractures in type 2 diabetes: a meta-analysis. CMAJ 180:32-39

5. Bazelier MT, de Vries F, Vestergaard P et al (2013) Risk of fracture with thiazolidinediones: an individual patient data meta-analysis. Front Endocrinol 4:1-9

6. Dormandy J, Bhattacharya M, van Troostenburg de Bruyn AR, investigators PR (2009) Safety and tolerability of pioglitazone in high-risk patients with type 2 diabetes: an overview of data from PROactive. Drug Saf 32:187-202

7. Home PD, Pocock SJ, Beck-Nielsen H et al (2009) Rosiglitazone evaluated for cardiovascular outcomes in oral agent combination 
therapy for type 2 diabetes (RECORD): a multicentre, randomised, open-label trial. Lancet 373:2125-2135

8. Kahn SE, Zinman B, Lachin JM et al (2008) Rosiglitazoneassociated fractures in type 2 diabetes: an analysis from A Diabetes Outcome Progression Trial (ADOPT). Diabetes Care 31:845-851

9. Solomon DH, Cadarette SM, Choudhry NK, Canning C, Levin R, Sturmer T (2009) A cohort study of thiazolidinediones and fractures in older adults with diabetes. J Clin Endocrinol Metab 94:2792-2798

10. Douglas IJ, Evans SJ, Pocock S, Smeeth L (2009) The risk of fractures associated with thiazolidinediones: a self-controlled case-series study. PLoS Med 6:e1000154

11. Grey A (2008) Skeletal consequences of thiazolidinedione therapy. Osteoporos Int 19:129-137

12. Bilezikian JP, Josse RG, Eastell R et al (2013) Rosiglitazone decreases bone mineral density and increases bone turnover in postmenopausal women with type 2 diabetes mellitus. J Clin Endocrinol Metab 98:1519-1528

13. Borges JL, Bilezikian JP, Jones-Leone AR et al (2011) A randomized, parallel group, double-blind, multicentre study comparing the efficacy and safety of Avandamet (rosiglitazone/metformin) and metformin on long-term glycaemic control and bone mineral density after 80 weeks of treatment in drug-naive type 2 diabetes mellitus patients. Diabetes Obes Metab 13:1036-1046

14. Grey A, Bolland M, Gamble G et al (2007) The peroxisome proliferator-activated receptor- $\gamma$ agonist rosiglitazone decreases bone formation and bone mineral density in healthy postmenopausal women: a randomized, controlled trial. J Clin Endocrinol Metab 92:1305-1310

15. Grey A, Bolland M, Fenwick S et al (2014) The skeletal effects of pioglitazone in type 2 diabetes or impaired glucose tolerance: a randomized controlled trial. Eur J Endocrinol 170:255-262

16. Berberoglu Z, Yazici AC, Demirag NG (2010) Effects of rosiglitazone on bone mineral density and remodelling parameters in postmenopausal diabetic women: a 2-year follow-up study. Clin Endocrinol 73:305-312

17. Zinman B, Haffner SM, Herman WH et al (2010) Effect of rosiglitazone, metformin, and glyburide on bone biomarkers in patients with type 2 diabetes. J Clin Endocrinol Metab 95:134-142

18. Gruntmanis U, Fordan S, Ghayee HK et al (2010) The peroxisome proliferator-activated receptor- $\gamma$ agonist rosiglitazone increases bone resorption in women with type 2 diabetes: a randomized, controlled trial. Calcif Tissue Int 86:343-349

19. Higgins JPT, Green S (editors). Cochrane handbook for systematic reviews of interventions version 5.1.0 [updated March 2011]. The Cochrane Collaboration, 2011. Available from www.cochranehandbook.org.

20. Berberoglu Z, Gursoy A, Bayraktar N, Yazici AC, Bascil Tutuncu N, Guvener Demirag N (2007) Rosiglitazone decreases serum bone-specific alkaline phosphatase activity in postmenopausal diabetic women. J Clin Endocrinol Metab 92:3523-3530

21. Kanazawa I, Yamaguchi T, Yano S et al (2010) Baseline atherosclerosis parameter could assess the risk of bone loss during pioglitazone treatment in type 2 diabetes mellitus. Osteoporos Int 21:20132018

22. Schindler K, Rieger A, Tura A et al (2009) The effect of rosiglitazone on insulin sensitivity, beta cell function, bone mineral density, and body composition in HIV-positive patients on highlyactive antiretroviral therapy (HAART). Horm Metab Res 41: 573-579

23. Glintborg D, Andersen M, Hagen C, Heickendorff L, Hermann AP (2008) Association of pioglitazone treatment with decreased bone mineral density in obese premenopausal patients with polycystic ovary syndrome: a randomized, placebo-controlled trial. J Clin Endocrinol Metab 93:1696-1701

24. Higgins JP, White IR, Wood AM (2008) Imputation methods for missing outcome data in meta-analysis of clinical trials. Clin Trials 5:225-239

25. Bone HG, Lindsay R, McClung MR, Perez AT, Raanan MG, Spanheimer RG (2013) Effects of pioglitazone on bone in postmenopausal women with impaired fasting glucose or impaired glucose tolerance: a randomized, double-blind, placebo-controlled study. J Clin Endocrinol Metab 98:4691-4701

26. Bray GA, Smith SR, Banerji MA et al (2013) Effect of pioglitazone on body composition and bone density in subjects with prediabetes in the ACT NOW trial. Diabetes Obes Metab 15:931-937

27. Harris VW, McComsey G, Chen H, et al (2011) The effects of rosiglitazone and metformin on longitudinal changes in bone mineral density and bone turnover markers in non-diabetic HIV-infected persons with lipodystrophy: a secondary analysis of aids clinical trial group (ACTG) A5082. Endocr Rev 32: Meeting Abstracts (Abstract)

28. Harslof T, Wamberg L, Moller L et al (2011) Rosiglitazone decreases bone mass and bone marrow fat. J Clin Endocrinol Metab 96:1541-1548

29. Henriksen K, Byrjalsen I, Qvist P et al (2011) Efficacy and safety of the PPAR $\gamma$ partial agonist balaglitazone compared with pioglitazone and placebo: a phase III, randomized, parallel-group study in patients with type 2 diabetes on stable insulin therapy. Diabetes Metab Res Rev 27:392-401

30. Maalouf N, Lingvay I, Huet B et al (2014) Pioglitazone increases femoral neck bone marrow fat content and proportionately reduces total hip bone mineral density. Endocr Rev 35: OR22-25 (Abstract)

31. Ross AC, Hileman CO, Brown TT et al (2012) Bone effects of rosiglitazone in HIV-infected patients with lipoatrophy. HIV Clin Trials 13:212-221

32. Tungsiripat M, Bejjani DE, Rizk N et al (2010) Rosiglitazone improves lipoatrophy in patients receiving thymidine-sparing regimens. AIDS 24:1291-1298

33. van Lierop AH, Hamdy NA, van der Meer RW et al (2012) Distinct effects of pioglitazone and metformin on circulating sclerostin and biochemical markers of bone turnover in men with type 2 diabetes mellitus. Eur J Endocrinol 166:711-716

34. Boehringer Ingelheim (2014) 30 week parallel group comparison study of linagliptin + pioglitazone $(5+15,5+30$ and $5+45 \mathrm{mg}) \mathrm{qd}$ versus respective monotherapies, followed by a comparison of $5 \mathrm{mg}+30 \mathrm{mg}$ and $5 \mathrm{mg}+45 \mathrm{mg}$ versus respective monotherapies in type 2 diabetes for up to 54 weeks. Available from https:// clinicaltrials.gov/ct2/show/NCT01183013, accessed 5 Jan 2015

35. Portillo Sanchez P, Bril F, Lomonaco R et al (2014) Effects of extended pioglitazone treatment (PIO) on bone metabolism in patients with prediabetes and type 2 diabetes mellitus (T2DM). Diabetes 63:A293-A294 (Abstract)

36. Hannan MT, Felson DT, Dawson-Hughes B et al (2000) Risk factors for longitudinal bone loss in elderly men and women: the Framingham Osteoporosis Study. J Bone Miner Res 15:710-720

37. Schwartz AV, Sellmeyer DE, Vittinghoff E et al (2006) Thiazolidinedione use and bone loss in older diabetic adults. J Clin Endocrinol Metab 91:3349-3354

38. Sardone LD, Renlund R, Willett TL, Fantus IG, Grynpas MD (2011) Effect of rosiglitazone on bone quality in a rat model of insulin resistance and osteoporosis. Diabetes 60:3271-3278

39. Stunes AK, Westbroek I, Gustafsson BI et al (2011) The peroxisome proliferator-activated receptor (PPAR) $\alpha$ agonist fenofibrate maintains bone mass, while the PPAR $\gamma$ agonist pioglitazone exaggerates bone loss, in ovariectomized rats. BMC Endocr Disord $11: 11$ 
40. Schwartz AV, Vittinghoff E, Margolis KL et al (2013) Intensive glycemic control and thiazolidinedione use: effects on cortical and trabecular bone at the radius and tibia. Calcif Tissue Int 92:477-486

41. Delmas PD, Eastell R, Garnero P, Seibel MJ, Stepan J, Osteoporosis CSAI (2000) The use of biochemical markers of bone turnover in osteoporosis. Osteoporos Int 11:2-17

42. Gerdhem P, Isaksson A, Akesson K, Obrant KJ (2005) Increased bone density and decreased bone turnover, but no evident alteration of fracture susceptibility in elderly women with diabetes mellitus. Osteoporos Int 16:1506-1512

43. Bolland MJ, Grey A, Reid IR (2015) Skeletal health in adults with HIV infection. Lancet Diabetes Endocrinol 3:63-74

44. Rogers A, Hannon RA, Eastell R (2000) Biochemical markers as predictors of rates of bone loss after menopause. J Bone Miner Res 15:1398-1404

45. Wan Y, Chong LW, Evans RM (2007) PPAR- $\gamma$ regulates osteoclastogenesis in mice. Nat Med 13:1496-1503
46. Benvenuti S, Cellai I, Luciani P et al (2007) Rosiglitazone stimulates adipogenesis and decreases osteoblastogenesis in human mesenchymal stem cells. J Endocrinol Invest 30:RC26-RC30

47. Bruedigam C, Eijken M, Koedam M et al (2010) A new concept underlying stem cell lineage skewing that explains the detrimental effects of thiazolidinediones on bone. Stem Cells 28:916-927

48. Soroceanu MA, Miao D, Bai XY, Su H, Goltzman D, Karaplis AC (2004) Rosiglitazone impacts negatively on bone by promoting osteoblast/osteocyte apoptosis. J Endocrinol 183:203-216

49. Mabilleau G, Mieczkowska A, Edmonds ME (2010) Thiazolidinediones induce osteocyte apoptosis and increase sclerostin expression. Diabet Med 27:925-932

50. Neve A, Corrado A, Cantatore FP (2011) Osteoblast physiology in normal and pathological conditions. Cell Tissue Res 343:289-302

51. Zhu ZN, Jiang YF, Ding T (2014) Risk of fracture with thiazolidinediones: an updated meta-analysis of randomized clinical trials. Bone 68:115-123 